\title{
Research on the Ecological Construction of Transnational Mother Tongue Language Under the Background of Rural Rejuvenation
}

\author{
Cailing $\mathrm{Xu}^{1, \mathrm{a}}$
}

\author{
${ }^{I}$ School of Language and Culture \\ Chuxiong Normal University Chuxiong China \\ axucailing24680@163.com
}

\begin{abstract}
The emergence of the concept of ecological language is based on the transformation of current ecology. Under the premise that social ecology is transformed into cultural ecology and spiritual ecology, humanities have an important position in ecology. The reason why humanity can exist in ecology is based on beliefs, customs, values, and other factors that make people's ecological behaviors different. The process of rural revitalization continues to change the ethnic population structure. While economic development brings unlimited opportunities to all ethnic groups, it also impacts the ethnic minority language ecology. The development of ethnic languages presents diverse changes under the influence of urbanization, education, and the economy.
\end{abstract}

Keywords: rural revitalization, cross-border ethnic groups, linguistic ecology, ethnic identity.

\section{INTRODUCTION}

The native language of ethnic minorities is their unique language, and there is naturally a difference in the sense of identity gained by using Chinese and the unique language when communicating with them. For ethnic minorities to develop, they must communicate in Chinese. Over time, the number of ethnic minorities who can speak Chinese has increased, but the number of people who can proficiently use the national language has decreased. We should take certain protection measures for minority languages, which requires research on the identity of ethnic minorities from the perspective of minority languages.

\section{THE CURRENT ECOLOGICAL ENVIRONMENT OF MINORITY LANGUAGES IN CHINESE}

Chinese is a country with a long history and a large number of ethnic groups. Among them, there are many kinds of languages. According to rough statistics, there are more than 130 kinds of languages in our country, and there is a phenomenon of a minority using multiple languages, which makes the ecology of minority languages in our country appear. The state of diversification. The current language ecological environment has been weakened a lot. In ancient China, the Chinese experienced many wars and disasters, and more languages were lost in the process. Based on modern research, although the phenomenon of language loss can be contained, in the general Chinese environment, the loss still develops slowly, and the scope of use of many languages has gradually decreased, such as Gelao. But some have already hard to find a trace, such as Manchu. From the perspective of the development of the language ecological environment, if time passes, Chinese will become the only language in our country, and the colorful culture of our country will disappear.

Based on statistics, there are more than 60 types of modern Chinese characters. As with languages, there is also the use of multiple scripts among a minority nationality. The scripts of these ethnic minorities have been perfected and formed under the impetus of history and have undergone many tests and practices, which proves the huge cultural value. Based on the function of writing, ethnic minorities prefer to use ethnic languages in communication, education, and politics, which can promote the development of ethnic minorities. However, based on the analysis of the current situation, some ethnic minorities, under the influence of Chinese, directly use Chinese characters as the common language 
of their nation. This confirms the versatility of Chinese and the loss of characters in the cultural-ecological environment phenomenon.

In both the languages and scripts of ethnic minorities, there is a phenomenon of diversification and weakening, which, to a certain extent, has led to the phenomenon of poor language vitality of ethnic minorities. Poor language vitality refers to the range of language use, application range, frequency, and other aspects. Among the various levels of human activities, the wider the scope of use and the more levels, the stronger the vitality of the language. The languages of ethnic minorities are first based on the foundation, because the population of ethnic minorities is small, so the foundation of language vitality deviates. Later, under the rule of various dynasties in ancient times, various political methods were used to force ethnic minorities to accept The Han language; secondly, the transition to modern times, under the influence of the social environment, makes Han culture continue to have an impact on ethnic minorities, and finally weakens the use of ethnic minority languages again, and then under a series of influences, it is confirmed the phenomenon of poor vitality of minority languages. Besides, due to the poor vitality of minority languages and the high degree of sinicization of the new generation of ethnic minority personnel, the frequency of the use of minority languages has decreased. Therefore, it is confirmed that the phenomenon of poor vitality of minority languages is still declining.

\section{ANALYSIS OF FACTORS AFFECTING CHINESE LANGUAGE ON MINORITY LANGUAGES}

The rule of the ancient dynasties of our country made Chinese the mainstream language ecological environment at that time, and because of political exchanges, it promoted the development of ethnic minority cultures influenced by the Chinese, leading to the sinicization of ethnic minorities. Modern Chinese policies and laws all advocate Chinese. This background also allows ethnic minorities to learn Chinese, which in turn makes some ethnic minorities have a deeper sense of identity with Chinese, and finally abandoned their own traditional culture and began to use it directly.

The material environment of modern society makes the survival and development of ethnic minorities inevitably inseparable from a certain economic foundation, and the standards of this economic foundation are gradually increasing. This makes ethnic minorities have to communicate more with Han culture. Only with good communication can economic growth be achieved. In the past, the survival of ethnic minorities mainly relied on the support of self-produced agriculture. Under this premise, the demand for Chinese was not large. However, as the degree of development increases, the industries and commerce of ethnic minorities have gradually grown. Development requires a lot of good communication to ensure the benefits of the industry. Under the general environment of Chinese, to make the industry competitive, it is necessary to learn Chinese. Due to the promotion of the economic environment, Chinese is widely used among ethnic minorities.

Driven by modern society, ethnic minorities have gradually begun to pay attention to the quality of education. However, the education environment of ethnic minorities is not good, and the quality of schools is generally low. To obtain a better education, they will pay more attention to the quality of education. Investing in schools for the Han nationality has allowed ethnic minority students to enter an environment that is entirely Chinese, and they will be able to absorb Chinese culture with their ears and eyes. Most prestigious schools and colleges in modern society are teaching Chinese, and there are not many special courses and subjects for minority language teaching. Therefore, when ethnic minorities receive education, they not only need to actively understand the Chinese language and Han culture, but also the influence of the general environment. Under the impetus of the two states, ethnic minority students will become Sinicized in a short period. Take the ethnic minority students in the 1990s and 2000s as an example. Based on their language mastery, they can be divided into three categories: first, able to use the national language and Chinese proficiently; second Language, but can use Chinese proficiently; third, proficient in the national language, but can not use Chinese well. The first type of minority students accounted for $21 \%$, the second type of minority students accounted for $46 \%$, and the third type of minority students accounted for $33 \%$. Through the statistics of data, we can see the mastery of Chinese and ethnic languages of contemporary students, which confirms the influence of the Chinese education environment on the languages of ethnic minorities.

\section{ANALYSIS OF ETHNIC IDENTITY IN MINORITY LANGUAGES}

Communication is an inevitable and indispensable link in human society. Every nation has its customary language that is its mother tongue. Mother tongue communication can promote smooth communication and contribute to the development and growth of society and individuals. If ethnic minorities can get more opportunities to use their mother tongue in various living environments, then cultural exchanges will be enhanced, and the loss of traditional culture will be avoided. At the same time, such a life will feel even more for ethnic minorities. Comfortable, good help in physical and mental health. Based on the survey, the vast majority of ethnic minorities are more willing to use ethnic languages in their lives, and ethnic languages 
are better than Chinese in terms of identity. Moreover, based on the ethnic minority population as a whole, most people from ethnic minorities over the age of 40 can only speak the national language and have little or no understanding of Chinese. Such people have a sense of identity with the national language in terms of daily communication.

There are some ethnic minority people whose growth environment belongs to the ethnic-cultural environment. When they reach the age of receiving education, to ensure the quality of education, they will go to Han schools for education. Such students need to learn Chinese and culture while receiving the content of the education itself. This reduces their sense of identity with the Chinese in two aspects. In addition to the content of the study itself, it is also necessary to learn Chinese that they do not understand. Under the effect of dual factors, these students often have a lower sense of identity with Chinese, and they are more dependent on the national language on the psychological level. A deeper sense of identity.

Based on the formation of language and culture, it is related to history, customs, culture, beliefs, and other aspects. In different language environments, there are certain differences in the development direction and purpose of the industries established. So from the perspective of development, if a few ethnic-cultural enterprises and Han cultural enterprises are in contact with each other, it is very likely that language

Cultural conflicts, incomprehension, and other phenomena have implemented development strategies fail. Analyzed from the perspective of psychology, because the contact failed, it would form an impression of Han cultural enterprises in the subconsciousness of ethnic minority industry personnel, that is, they are the development targets of enterprises that are difficult to succeed, so in terms of identity, Will be more inclined to enterprises with traditional national culture. And such a development direction, based on the size of minority enterprises, has a great delay in the speed of development and therefore forces minority enterprises to learn Han culture to facilitate communication with Han cultural enterprises. In the process of learning, you may also come into contact with factors that your own national culture does not identify with, which may deepen your disapproval of Han culture.

Family communication is the most basic way of life communication for ethnic minorities. On this basis, if ethnic minorities can get more opportunities to use the ethnic language in the family, it will help the inheritance of ethnic culture. . However, based on the size of the family, the age range is relatively large, and the elders in some ethnic minority families tend to be more proficient in using traditional ethnic languages but not in Chinese. This is when children in the family communicate with their elders. At times, there will be an inconvenience in communication, which is likely to cause dissatisfaction among the elders. Based on this status quo, it will greatly reduce the elders' sense of identification with Chinese, believing that Chinese makes children unable to use their mother tongue, which has an adverse effect.

Chinese has a dominant position in the language ecological environment. To protect minority languages and ensure that they can be passed down intact, it is necessary to increase the opportunities for minority languages to be used by people, so the implementation of bilingualism is necessary. The implementation of bilingualism is to guide the environment, careers, and people from the aspects of law, policy, etc. to education, life, industrial development, and family concepts, so that it pays attention to the traditional languages of ethnic minorities. In terms of education, through policy guidance, we should first build more bilingual schools in minority areas, and carry out minority language education courses on the premise of ensuring the quality of teaching, so that Han students can learn minority languages. Enhance communication between nations.

\section{CHANGES IN THE ROOT CULTURE OF THE NATIVE LANGUAGE}

China has a history of more than five thousand years. The splendid civilization has created the diversity of Chinese culture. Among them, the diversity of language is an extremely precious treasure of Chinese culture; under the bred of Taoist and Confucian wisdom, the Chinese nation carries the essence of Chinese culture" Rootedness". The root culture of the native language is a kind of national identity consciousness, it is the emotional attitude and loyalty to the native language; the root culture of the native language affects the vitality of the language and the inheritance of the language [1], and plays an important role in the balance of the language ecology.

\subsection{Native language root culture and language vitality}

There are phenomena of pidginization and realization in the evolution of language. Both phenomena are related to the interaction and combination of two or more parent languages to produce new languages. Creoleization is a higher stage of pidginization. Language is dynamic. Phenomenon such as language substitution, language conversion, simultaneous use of languages, Chinese loanwords, bilingual or multilingualism, etc., not only challenge the development of traditional national languages but also enrich the diversity of languages. In the coexistence of multiple languages, the root culture of the mother tongue plays a key role in preventing the pidginization and realization of the language. There are strong and 
weak languages in the language ecological environment. The strength of the root culture of the native language directly affects the strength of the language's vitality, and subsequently affects the self-growth and development trend of the language.

\subsection{Reasons for the cultural change of the native language}

As mentioned above, the root culture of the native language is a kind of national identity. It is the emotional attitude and loyalty to the native language. It has an important influence on the vitality of the language. The loyalty of the population to the native language and native culture is passed on from generation to generation, making the native language Maintain tenacious vitality [2]. Take the Bai people's attitude towards Bai language as an example. When the Bai people use Bai language, there is an unwritten rule that "the Bai people must speak the Bai language when they see the Bai people". If people of the same race speak Chinese, they will be regarded as impolite, and they will be looked down upon and rejected.

The change of the root culture of the mother tongue is affected by many aspects. Root culture is a kind of consciousness and idea, and consciousness and idea are different because of different education levels, so the change of native language root culture is closely related to national sentiment and education level [3]. The economic foundation determines the superstructure, and urbanization and economic development have changed the population distribution structure and impacted the ecological balance of language. Because most ethnic minorities live in relatively remote and backward areas, and in an environment where ethnic sentiments are diluted, if young people do not receive more cultural education, their awareness of the protection of their mother tongue and ethnic culture will naturally become weak. Besides, the impact of educational level on the root culture of the mother tongue is also reflected in the changes in the parents' educational philosophy for their children. Parents use their educational level as the value basis and believe that strong communicative language is more likely to bring employment opportunities for their children. In order not to affect their children's mastery of strong language, parents no longer preach the national mother tongue, which directly causes "intergenerational interruption."

\subsection{The root culture of native language and language ecology}

Since the reform and opening up for 40 years, the rapid economic development has continuously strengthened the communicative function of Chinese, making it the common communicative language of 56 ethnic groups. The status of the languages of all ethnic groups is equal, but because of the differences in the use of functions, Chinese has become a strong language. The process of urbanization has changed the population distribution of ethnic minorities, and the change in population size fundamentally affects language development. The key to achieving harmonious coexistence of various ethnic languages and maintaining a good language ecology lies in how to allow weak languages to develop themselves healthily and have strong language vitality. Languages compete due to functional differences, which are manifested in the competition between strong and weak languages [4]. Language competition usually has three results: "One is that competing languages coexist for a long time, and they absorb and penetrate each other in mutual contact, and develop together in complementarity. Weak languages will not decay or be replaced due to competition and are always in their use. It plays an irreplaceable role within the scope; the second is that in the competition, the strong are stronger and the weaker are weaker, resulting in the Matthew effect'; and the third is that the weaker language completely loses competitiveness in the competition and is on the verge of endangerment, or even complete extinction. In the context of language competition, the root culture of the native language is an important condition for the selfdevelopment of weak languages and resistance to strong language attacks.

\section{CONCLUSION}

Overall, cross-border ethnic languages are an important part of Chinese traditional culture, but the current loss is more serious. Under the current background of rural revitalization, to avoid loss, it is necessary to analyze the language and ecological environment and obtain specific influencing factors to take targeted measures to improve it.

\section{REFERENCES}

[1] C Hagège. L'Homme de paroles. 1996.

[2] Glausiusz, Josie. The ecology of language. Discover, 1997.

[3] R Phillipson. A Human Rights Perspective on Language Ecology. 2008.

[4] R Terborg, L G Landa. The Ecology of Pressures: Towards a Tool to Analyze the Complex Process of Language Shift and Maintenance. 